\title{
LEVANTAMENTO E CARACTERÍSTICAS ECOLÓGICAS DE ORCHIDACEAE DA MATA CILIAR DO RIO DOURADOS, DOURADOS-MS ${ }^{1}$
}

\author{
André Rodrigo Rech², Yara Brito Chaim Jardim Rosa ${ }^{3}$ e Edgard Jardim Rosa-Junior ${ }^{3}$
}

RESUMO - A família Orchidaceae é uma das maiores entre as plantas com flores e apresenta grande importância do ponto de vista da conservação. Apesar disso, não existe nenhum trabalho sobre as orquídeas de Mato Grosso do Sul. Nesse sentido, o objetivo desta pesquisa foi realizar o levantamento das espécies de Orchidaceae e de aspectos de sua ecologia na Mata Ciliar de um fragmento de Floresta Estacional Semidecidual, às margens do rio Dourados (Dourados, MS). O levantamento foi realizado em sistema de varredura, sendo, nas epífitas, avaliadas as disposições vertical e horizontal sobre os forófitos. Para caracterização do microclima foram utilizados termo-higrômetro e luxímetro. Identificaram-se 17 espécies, pertencentes a 13 gêneros. Dos gêneros levantados, os de maior abundância foram: Acianthera, Macradenia e Capanemia. Relacionaram-se, ainda, as disposições vertical e horizontal das Orchidaceae com os gradientes inversos de disponibilidades hídrica e luminosa. Algumas espécies mostraram-se sensíveis à categorização em níveis de altura, enquanto outras pareciam ocorrer com frequência similar ao longo de todo o forófito. Em relação à orientação cardeal, a aparente resposta preferencial pelas faces sul e leste foi associada à insuficiência amostral e à menor disponibilidade hídrica que poderia ocorrer em razão de a face norte estar oposta ao espelho d’água.

Palavras-chave: Orquídeas, Epifitismo e Taxonomia.

\section{INVENTORY AND ECOLOGIC FEATURES OF ORCHIDACEAE IN THE RIO DOURADOS RIPARIAN FOREST, DOURADOS-MS}

\begin{abstract}
Inventory and ecologic features of Orchidaceae in the Rio Dourados riparian Forest, Dourados-MS). The Orchidaceae is one of the largest flowering plants family and with a great importance to conservation. However, no survey on orchid flowers can be found in Mato Grosso do Sul. Thus, the objective of this work was to make a survey of the Orchidaceae species and of its ecology features in a riparian forest in a fragment of Floresta Estacional Semi-Decidual that belongs to the riparian forest of the Dourados River. The inventory was made by using a sweeping method for collection, and in addition to this the vertical and horizontal position of epiphytes were assessed on the hosts. For characterization of microclimate, it was used a thermohygrometer and luximeter. It was identified 17 species of 13 genera. Of the listed genera, the most abundant ones were: Acianthera, Macradenia and Capanemia. It was also noted a vertical and horizontal distribution of the Orchidaceae in relation to inverse gradient of water and light availability. Some species tended to be sensitive to height level categorization, whereas others seemed to occur with similar frequency along the host. In relation to the cardinal orientation, the apparent preferential response for south and east directions was associated to the low sampling effort and lower water availability, which could occur because the north face is opposed to the water body.
\end{abstract}

Keywords:Epifitism, Taxonomy and Orchid flower.

\footnotetext{
${ }^{1}$ Recebido em 31.07.2009 e aceito para publicação em 18.04.2011.

${ }^{2}$ Universidade Estadual de Campinas, UNICAMP, Brasil. E-mail: <arech2003@yahoo.com.b>.

${ }^{3}$ Universidade Federal da Grande Dourados, UFGD, Brasil. E-mail: <yararosa@ufgd.edu.br> e <edgardjunior@ufgd.edu.br>.
} 


\section{INTRODUÇÃO}

Orchidaceae é uma das maiores famílias de Angiospermas, possuindo cerca de 19.500 espécies, distribuídas entre 788 gêneros, dispersas em quase todo o mundo, com maior diversidade na região tropical (JUDD et al., 2009). Nessa região, o Brasil destaca-se por apresentar 12,05\% da flora mundial de Orchidaceae, com cerca de 2.650 espécies (205 gêneros), das quais aproximadamente 1.800 (35 gêneros) são endêmicas (GIULIETTI et al., 2005).

No Cerrado brasileiro, Mendonça et al. (1998) compilaram 491 espécies (91 gêneros) de Orchidaceae. Já na Região Centro-Oeste existem os registros de 78 espécies citadas por Lima (1985), no Estado de Mato Grosso, e de 61 citadas por Batista e Bianchetti (2003) no Distrito Federal. Apenas os trabalhos de Hoehne (1923) e Hoehne e Kuhlmann (1951) trazem informações acerca das Orchidaceae que poderiam ocorrer no Estado de Mato Grosso do Sul. No entanto, há um grau de incerteza nessas listas em função de esses trabalhos precederem à divisão política do Estado e, portanto, não há como precisar quais espécies ocorrem especificamente nos atuais Estados de Mato Grosso e Mato Grosso do Sul.

Entre as espécies da família Orchidaceae existe variedade muito grande de hábitos, predominando as epífitas nas regiões tropicais e um gradiente progressivo de aumento de espécies terrícolas à medida que ocorre o distanciamento da linha do Equador (GENTRY, 1988). No entanto, ocorrem ainda na família espécies rupícolas, paludícolas e saprofíticas. Na área de ocorrência da Floresta Estacional Semidecidual no Brasil já foram realizados alguns estudos acerca das orquídeas, os quais, além da hábitos, também investigaram aspectos ecológicos do epifitismo. Entre esses trabalhos, destacam-se os de Pinto et al. (1995) em um fragmento de floresta no Estado de São Paulo, de Aguiar et al. (1981) no Rio Grande do Sul e de Dislich e Mantovani (1998) na cidade de São Paulo.

Este estudo teve por objetivos levantar as espécies de Orchidaceae em uma porção de Mata Ciliar do rio Dourados, em Dourados, MS, descrever aspectos ecológicos e confeccionar uma chave de identificação rápida dessas espécies.

\section{MATERIAL E MÉTODOS}

O estudo foi desenvolvido em Dourados, na porção sul do Estado de Mato Grosso do Sul (22 $2^{\circ} 21^{\prime} 03^{\prime \prime S}$ e 54²7’07"W GRW), em uma reserva particular (Estância
Aurora) às margens do rio Dourados, a aproximadamente $458 \mathrm{~m}$ de altitude. O clima da região é úmido com inverno seco, precipitação média anual de $1.500 \mathrm{~mm}$ e temperatura média anual de $22{ }^{\circ} \mathrm{C}$. O solo da região é classificado como Latossolo Vermelho Distroférrico, formado a partir da degradação de rocha basáltica. O rio Dourados é tributário da Bacia do Paraná e a vegetação no local é de Floresta Estacional Semidecidual (SEPLAN, 1990).

O trabalho foi realizado ao longo de um transecto, na Mata Ciliar, à margem esquerda do rio, cuja largura média do espelho d’água era de $50 \mathrm{~m}$, sendo toda a área estudada uma reserva legal averbada (Código Florestal - Lei 4.771/65 e acréscimos). O transecto foi subdividido em 30 secções de 100 x 10 m cada (parcelas), totalizando três hectares. Optou-se por amostrar 3 ha, ou seja, o dobro do esforço amostral proposto por Silva e Scariot (2004) para Floresta Estacional, uma vez que a área deste estudo já sofreu certo grau de antropização e possivelmente extrativismo de Orchidaceae. Em cada secção foram analisados todos os forófitos (árvores, troncos secos, lianas e arbustos) e o solo. Realizaram-se excursões mensais de coleta e aferições das condições microclimáticas entre agosto de 2006 e julho de 2007, e de cada espécie fértil foram coletadas três amostras de espécimes diferentes (quando possível), para herborização. O material-testemunho foi depositado no Herbário da Universidade Federal da Grande Dourados (A. R. Rech 01 - 17). A determinação das autorias taxonômicas foi realizada de acordo com a base de dados Tropicos (www.tropicos.org).

O número absoluto de parcelas em que cada espécie ocorreu foi tratado como frequência. Em cada parcela do transecto foi registrado o número de indivíduos ou indivíduos-touceiras (JACOBI et al., 2008) de cada espécie. Para cada indivíduo, registrou-se a hábitos (epífita, terrícola, rupícola etc.) e para as epífitas, a localização no forófito (ramo ou forquilha), a disposição horizontal (orientação em relação aos pontos cardeais) e vertical (nível 1: abaixo de $2 \mathrm{~m}$, nível 2: entre 2 e $4 \mathrm{~m}$ e nível 3: acima de $4 \mathrm{~m}$ ). Mensalmente, foi feita a caracterização do microclima nas parcelas, com registro das condições de temperatura do bulbo seco, umidade relativa do ar e luminosidade difusa média à altura do peito, por meio de 15 aferições por parcela.

Revista Árvore, Viçosa-MG, v.35, n.3, Edição Especial, p.717-724, 2011 


\section{RESULTADOS}

Foram identificadas 17 espécies, pertencentes a 13 gêneros, todos inseridos na subfamília Epidendroideae (Tabela 1). Na tribo Cymbideae foi registrada a subtribo Oncidiinae: Macradenia multiflora (Kraenzl.) Cogn., Oncidium jonesianum Rchb. F, Trichocentrum cebolleta (Jacq.) M.W. Chase e N.H. Williams e Trichocentrum pumilum (Lindl.) M. W. Chase e N.H. Williams. Na tribo Epidendreae foram registradas as subtribos Laeliinae: Brassavola ceboletta Rchb. F., Leptotes unicolor Barb. Rodr. e Laelia lundii Rchb. F. e Pleurothallidinae: Acianthera aff. macuconensis, Acianthera pubescens (Lindl.) Pridgeon e M.W. Chase, Acianthera recurva (Lindl.) Pridgeon e M.W. Chase, Specklinia aff. montepelladensis. Na Tribo Vandae, registraram-se as subtribos Angraecinae: Campylocentrum burchellii Cogn. e Polystachyinae: Polystachya concreta (Jacq.) Garay e H.R. Sweet. Bulbophyllum micranthum Hook F., Bulbophyllum tripetalum Lindl., Capanemia micromera Barb. Rodr. e Oeceoclades maculata (Lindl.) Lindl.

Nas espécies Macradenia multiflora e Oncidium jonesianum foi verificada variação natural de coloração (mais clara), entendida pelos autores como uma possível variedade. Entre os gêneros levantados, o de maior abundância foi Acianthera, seguido de Macradenia e Capanemia, enquanto o gênero mais rico em espécies foi Acianthera (três espécies). Quanto à distribuição biogeográfica, de acordo com a base de dados Tropicos (www.tropicos.org), apenas O. maculata e P. concreta apresentam distribuição pantropical, ocorrendo também na África e Ásia. As demais espécies são todas neotropicais, entre as quais $M$. multiflora, $P$. macuconensis e T. pumilum são citadas com presença apenas no Brasil (Tabela 2).

Com base nos caracteres morfológicos das espécies amostradas, foi elaborada a chave de identificação, como se segue:

Chave rápida para identificação das Orchidaceae da Estância Aurora, Dourados MS.

\section{Plantas áfilas.........Campylocentrum cf. burchellii}

1’. Plantas com folhas.

2. Polínias ceroides, raras vezes com viscídio.

3. Inflorescência lateral.

4. Coluna com projeções na face abaxial; inflorescência ereta; sépalas quase tão largas quanto compridas; pseudobulbo + folha maior que $5 \mathrm{~cm}$ alt........Bulbophylum tripetalum
4'. Coluna sem projeções; inflorescência nutante; sépalas mais compridas que largas; pseudobulbo + folha menor que $5 \mathrm{~cm}$ alt. Bulbophylum micranthum

3’. Inflorescência terminal.

5. Ovário não articulado com o pedicelo, acompanhando a flor quando esta se desprende; flores sem mento; polínias 6 ou 8 .

6.Polínias 6 Leptotes unicolor

6’. Polínias 8.

7. Caule secundário conspícuo, bifoliado; plantas menores que $15 \mathrm{~cm}$ alt.; folhas eretas.

Laelia lundii

7’. Caule secundário inconspícuo, unifoliado; plantas sempre maiores que $15 \mathrm{~cm}$ alt.; folhas pendentes.

Brassavola ceboletta

5’. Ovário articulado com o pedicelo de modo que permanece unido à raquis quando a flor se desprende; flores com mento; polínias 2 .

8. Caule secundário maior que $2 \mathrm{~cm}$ de compr.; flores predominantemente acastanhadas ou vináceas.

9. Inflorescência com até 2 cm de compr.; geralmente com 1-2 flores; flores externamente glabras

Acianthera aff. macuconensis

9’. Inflorescência com 3-5 cm de compr.; geralmente com 5 ou mais flores; flores externamente pubescentes

Acianthera pubescens

8'. Caule secundário menor que 2 cm de compr.; flores predominantemente esbranquiçadas ou amareladas.

10. Sépalas laterais unidas entre si, inflorescências sempre mais curtas que as folhas carnosas e rijas...... Acianthera recurva

10’. Sépalas laterais livres entre si; inflorescências maiores ou do mesmo comprimento das folhas delicadas.... Specklinia aff. montepelladensis

2’. Polínias cartilaginosas com viscídio e estipe.

11. Inflorescência terminal. 
Tabela 1 - Frequência (freq.) nas parcelas amostrais, abundância (ab.), localização (ramo/fuste, forquilha ou solo), frequência nos níveis de altura (1- abaixo de 2 m; 2- entre 2 e 4 m; 3- acima de 4 m ) e orientação em relação aos pontos cardeais das Orchidaceae sobre o forófito na Mata Ciliar da Estância Aurora, Dourados, MS. * não aplicável.

Table 1 - Frequency in (freq.) the sampling parcels, abundance (ab.), location (branch, fork or soil), frequency at height levels (1- below $2 \mathrm{~m}$; 2-between 2 and $4 \mathrm{~m}$; 3-above $4 \mathrm{~m}$ ) and orientation in relation to Orchidaceae cardinal points on the host treein the riparian forests of Estância Aurora, Dourados-MS. * not applicable.

\begin{tabular}{|c|c|c|c|c|c|c|c|c|c|c|c|c|c|}
\hline \multirow[t]{2}{*}{ Espécie } & \multirow[b]{2}{*}{ Freq. } & \multirow[b]{2}{*}{ Ab. } & \multicolumn{3}{|c|}{ Localização (\%) } & \multicolumn{3}{|c|}{$\begin{array}{l}\text { Frequência } \\
\text { nos níveis de } \\
\text { altura (\%) }\end{array}$} & \multicolumn{3}{|c|}{ Orientação (\%) } & \multirow[b]{2}{*}{$\mathrm{W}$} & \multirow[b]{2}{*}{$\begin{array}{l}\text { Envolvendo } \\
\text { o tronco }\end{array}$} \\
\hline & & & $\mathrm{Ra} / \mathrm{Fu}$ & Forq. & Solo & 1 & 2 & 3 & $\mathrm{~N}$ & $S$ & $\mathrm{E}$ & & \\
\hline $\begin{array}{l}\text { Acianthera aff. } \\
\text { macuconensis }\end{array}$ & 25 & 1039 & 100 & 0 & 0 & 67 & 31 & 2 & 13 & 18 & 21 & 21 & 27 \\
\hline $\begin{array}{l}\text { Acianthera pubescens } \\
\text { (Lindl.) Pridgeon e }\end{array}$ & & & & & & & & & & & & & \\
\hline $\begin{array}{l}\text { M.W. Chase } \\
\text { Acianthera recurva } \\
\text { (Lindl.) Pridgeon e }\end{array}$ & 8 & 126 & 99 & 1 & 0 & 29 & 63 & 8 & 0 & 71 & 24 & 5 & 0 \\
\hline $\begin{array}{l}\text { M.W. Chase } \\
\text { Brassavola ceboletta }\end{array}$ & 4 & 821 & 100 & 0 & 0 & 3 & 3 & 94 & 0 & 33 & 62 & 0 & 5 \\
\hline $\begin{array}{l}\text { Rchb. F } \\
\text { Bulbophyllum } \\
\text { micranthum }\end{array}$ & 13 & 279 & 89 & 11 & 0 & 24 & 33 & 43 & 18 & 30 & 25 & 16 & 11 \\
\hline $\begin{array}{l}\text { Hook F. } \\
\text { Bulbophyllum }\end{array}$ & 2 & 40 & 100 & 0 & 0 & 0 & 25 & 75 & 25 & 0 & 75 & 0 & 0 \\
\hline $\begin{array}{l}\text { tripetalum Lindl. } \\
\text { Campylocentrum }\end{array}$ & 1 & 3 & 100 & 0 & 0 & 0 & 0 & 100 & 0 & 0 & 0 & 0 & 100 \\
\hline $\begin{array}{l}\text { cf. burchellii Cogn. } \\
\text { Capanemia } \\
\text { micromera Barb. }\end{array}$ & 1 & 1 & 100 & 0 & 0 & 0 & 0 & 100 & 0 & 0 & 0 & 100 & 0 \\
\hline $\begin{array}{l}\text { Rodr. } \\
\text { Laelia lundii }\end{array}$ & 12 & 76 & 100 & 0 & 0 & 30 & 32 & 38 & 2 & 16 & 18 & 4 & 59 \\
\hline $\begin{array}{l}\text { Rchb. F } \\
\text { Leptotes unicolor }\end{array}$ & 6 & 72 & 100 & 0 & 0 & 57 & 29 & 14 & 0 & 1 & 14 & 15 & 69 \\
\hline $\begin{array}{l}\text { Barb. Rodr. } \\
\text { Macradenia } \\
\text { multiflora (Kraenzl.) }\end{array}$ & 4 & 8 & 100 & 0 & 0 & 0 & 38 & 62 & 25 & 63 & 13 & 0 & 0 \\
\hline $\begin{array}{l}\text { Cogn. } \\
\text { Oeceoclades } \\
\text { maculata (Lindl.) }\end{array}$ & 10 & 170 & 100 & 0 & 0 & 89 & 11 & 0 & 4 & 57 & 30 & 9 & 0 \\
\hline $\begin{array}{l}\text { Lindl. } \\
\text { Oncidium }\end{array}$ & 1 & 1 & 0 & 0 & 100 & 100 & 0 & 0 & * & $*$ & $*$ & * & $*$ \\
\hline $\begin{array}{l}\text { jonesianum Rchb. F } \\
\text { Polystachya } \\
\text { concreta (Jacq.) }\end{array}$ & 3 & 6 & 100 & 0 & 0 & 25 & 25 & 50 & 0 & 17 & 67 & 17 & 0 \\
\hline $\begin{array}{l}\text { Garay e H.R. Sweet. } \\
\text { Specklinia aff. }\end{array}$ & 1 & 1 & 0 & 100 & 0 & 100 & 0 & 0 & 0 & 100 & 0 & 0 & 0 \\
\hline $\begin{array}{l}\text { montepelladensis } \\
\text { Trichocentrum } \\
\text { cebolleta (Jacq.) } \\
\text { M.W. Chase e }\end{array}$ & 6 & 153 & 100 & 0 & 0 & 7 & 42 & 51 & 0 & 28 & 41 & 32 & 0 \\
\hline $\begin{array}{l}\text { N.H. Williams } \\
\text { Trichocentrum } \\
\text { pumilum (Lindl.) } \\
\text { M. W. Chase e }\end{array}$ & 1 & 3 & 100 & 0 & 0 & 0 & 0 & 100 & 0 & 0 & 100 & 0 & 0 \\
\hline N.H. Williams & 15 & 109 & 100 & 0 & 0 & 48 & 21 & 31 & 4 & 15 & 34 & 31 & 17 \\
\hline Geral & $*$ & 2.907 & 88 & 7 & 6 & 34 & 21 & 45 & 6,05 & 29,9 & 34,9 & 10 & 19,2 \\
\hline
\end{tabular}

Revista Árvore, Viçosa-MG, v.35, n.3, Edição Especial, p.717-724, 2011 
Tabela 2 - Distribuição das espécies amostradas em outras regiões do Brasil, de acordo com Pabst e Dungs (1975, 1977), e do mundo, segundo a base de dados do Missouri Botanical Garden (MOBOT).

Table 2 - Distribution of the sampled species in other Brazilian regions, according to according to Pabst and Dungs (1975, 1977) and in the world according to the database of the Missouri Botanical Garden (MOBOT).

\begin{tabular}{|c|c|c|}
\hline Espécie & $\begin{array}{l}\text { Distribuição mundial } \\
\text { (Tropicos - MOBOT) }\end{array}$ & $\begin{array}{l}\text { Distribuição no Brasil } \\
\text { (PABST; DUNGS, 1975, 1977) }\end{array}$ \\
\hline Acianthera aff. macuconensis & Brasil & MG \\
\hline Acianthera pubescens & América Latina do México ao Uruguai & BA, RJ, SP, PR, SC, RS \\
\hline Acianthera recurva & Argentina, Bolívia e Brasil & ES, RJ, SP, PR, SC, RS, MG \\
\hline Brassavola ceboletta & Bolívia, Paraguai, Peru e Brasil & $\mathrm{BA}, \mathrm{ES}, \mathrm{PR}, \mathrm{MG}, \mathrm{GO}, \mathrm{DF}$ \\
\hline Bulbophylum tripetalum & Argentina, Paraguai e Brasil & SP, PR \\
\hline Bulbophylum micranthum & Argentina, Colômbia e Brasil & MG, RJ, PR \\
\hline Campylocentrum cf. burchellii & Argentina, Colômbia e Brasil & AM, RJ, SP, PR, SC, RS, MG \\
\hline Capanemia micromera & Argentina, Bolívia, Paraguai e Brasil & MG \\
\hline Leptotes unicolor & Argentina, Paraguai e Brasil & PR, MG \\
\hline Laelia lundii & Argentina, Bolívia, Paraguai e Brasil & MG, GO, DF, MT \\
\hline Macradenia multiflora & Brasil & RS, MG, GO, MT \\
\hline Oeceoclades maculata & Pantropical & AM, AP, PA, ES, RJ, GB, PR, SC, MG, DF, MT \\
\hline Oncidium jonesianum & Argentina, Bolívia, Paraguai e Brasil & MG, SP, MT \\
\hline Polystachya concreta & Pantropical & $\begin{array}{l}\text { AM AP, PA, PE, AL, ES, MG, GO, MT, SE, BA, } \\
\text { RJ, PR, SC, RS }\end{array}$ \\
\hline Specklinia aff. montepelladensis & Brasil & $\mathrm{BA}, \mathrm{SP}, \mathrm{MG}$ e $\mathrm{MT}$ \\
\hline Trichocentrum cebolleta & América Latina do México ao Uruguai & AC, AM, RR, PA, PI, PE, BA, ES, MG, MT, GO \\
\hline Trichocentrum pumilum & Brasil & PA, BA, ES, RJ, SP, PR, SC, RS, MG, DF, GO, MT \\
\hline
\end{tabular}

12. Planta epífita; folhas inteiramente verdes, sem calcar.. Polystachya concreta

12’. Planta terrestre, folhas verde-escuras marmoreadas de verde-acinzentado, cálcar conspícuo.

\section{Oeceoclades maculata}

11’. Inflorescência lateral.

13. Folhas cilíndricas ou aciculares.

14. Plantas menores que $5 \mathrm{~cm}$ de alt.; inflorescência geralmente com até o mesmo comprimento da folha, flores sem manchas

Capanemia micromera

14'. Plantas maiores que $5 \mathrm{~cm}$ de alt., inflorescência sempre mais longa que a folha, flores com manchas castanhas.

15. Pedúnculo pêndulo, flores predominantemente brancas

Oncidium jonesianum

15’. Pedúnculo ereto, flores predominantemente amarelas Trichocentrum cebolleta

13’. Folhas planas.

16. Pseudobulbos ca. $15 \mathrm{~cm}$ de compr.; folhas membranáceas, inteiramente verdes sem pontuações.

Macradenia multiflora
16’. Pseudobulbos menores que 3 cm de compr.; folhas cartáceas, com inúmeras pontuações acastanhadas

Trichocentrum pumilum

Na avaliação da disposição horizontal (orientação cardeal) dos indivíduos sobre o forófito, verificou-se maior incidência das espécies nas faces Sul e Leste. Com relação à localização, todos os indivíduos amostrados ocorreram em ramos, exceto nas espécies Polystachya estrellensis, que foi registrada somente em forquilhas e Oeceoclades maculata, que é terrícola. No que tange à disposição vertical, registrou-se maior concentração das plantas nos níveis 1 e 3 (Tabela 1 ). As médias de temperatura, umidade relativa e luminosidade são apresentadas na Tabela 2.

\section{DISCUSSÃO}

Entre as espécies identificadas na área de estudo, oito foram citadas pela primeira vez em Mato Grosso do Sul (C. cf. burchellii, B. ceboletta, Bu. micranthum, Bu. tripetalum, Cap. micromera, L. unicolor, A. pubescens e $A$. recurva) e três são novas ocorrências na Região Centro-Oeste como um todo (B. tripetalum, A. pubescens e A. recurva) (HOEHNE, 1923; HOEHNE; KUHLMANN, 1951; PABST; DUNGS, 1975, 1977; LIMA, 1985; BATISTA; BIANCHETTI, 2003, BATISTA et al., 2005). 
Entre os estudos já realizados que trazem referência à flora de orquídeas de Mato Grosso do Sul, no trabalho de Hoehne (1923) as espécies Oncidium cebolleta (Jacq.) Sw. e Oncidium pumilum Lindl. (aqui tratadas como: T. cebolleta e T. pumilum), são tidas como exemplos da influência da vegetação do bioma Cerrado sobre a vegetação do Sul do Estado. Outras espécies (Oncidium macropetalum Lindl., Oncidium pusillum (L.) Rchb. f., Oncidium thyrsiflorum Barb. Rodr., Trichocentrum nanum (Lindl.) M.W. Chase e N.H. Williams) tidas por Hoehne (1923) como peculiares das matas do Sul do Estado, não ocorreram na área estudada. Na região que corresponderia ao atual Norte de Mato Grosso do Sul, Hoehne (1923) citou 36 espécies, entre as quais apenas M. multiflora foi registrada na área deste estudo.

Entre as espécies apresentadas por Hoehne e Kuhlmann (1951) para o Estado de Mato Grosso (que na época incluía Mato Grosso do Sul), cinco também foram registradas neste estudo. No entanto, O. maculata é citada nas cercanias de Cuiabá e T. cebolleta, M. multiflora e P. concreta o são na região a Nordeste de Cárceres. Dessa forma, a única espécie citada na atual circunscrição de Mato Grosso do Sul foi $O$. jonesianum, encontrada na região de Corumbá. De maneira geral, esses autores afirmaram que a região de Mato Grosso é “pobre” em Orchidaceae. De fato, quando comparada com as florestas atlântica ou amazônica, a riqueza de espécies parece ser menor. No entanto, este estudo e o de Lima (1985) demonstraram que ainda remanescem muitas espécies sem registro de ocorrência na região, indicando insuficiência de amostragem.

Do conjunto de espécies encontradas, o maior número de espécies compartilhadas se deu nos Estados do Paraná (cinco espécies), São Paulo (quatro espécies) e Distrito Federal (quatro espécies) (KERSTEN; SILVA, 2001, 2002; BATISTA; BIANCHETTI, 2003; BORGO; SILVA, 2003; BATISTAetal., 2005; CARDOSO; ISRAEL, 2005; TOZZO; CARVALHO, 2007; PANSARIN; PANSARIN, 2008). A composição de espécies encontrada na região estudada reflete a predominância de espécies da Floresta Estacional Semidecidual, mas congrega também elementos tanto de Floresta Ombrófila (e.g. A. recurva S. aff. montepelladensis) quanto do Cerrado (e. g. T. cebolleta e L. lundii). Esse mesmo padrão corrobora o que já foi registrado na florística de espécies arbóreas (RIZZINI, 1979; SALIS etal., 2004; SPICHIGER et al., 2004; PEREIRA et al., 2007). Considerando as espécies em função das formas de vida, reafirma-se a relação mais próxima com a vegetação do domínio atlântico, já que predominou
Tabela 3 - Valores médios de temperatura de bulbo seco (Tbs), umidade relativa do ar (UR) e luminosidade, registrados na Mata Ciliar do rio Dourados, Dourados, MT, Brasil, 2006-2007.

Table 3 - Mean values of dry bulb temperature, relative air humidity (UR) and luminosity, registered in the Rio Dourados riparian forest, Dourados, MT, 2006-2007.

\begin{tabular}{lccc}
\hline & \multicolumn{3}{c}{ Mata ciliar do rio Dourados } \\
\hline Estações & Tbs $\left({ }^{\circ} \mathrm{C}\right)$ & UR(\%) & Luminosidade(lux) \\
\hline Primavera & 25,6 & 73,1 & 853,8 \\
Verão & 24,1 & 75,2 & 415,3 \\
Outono & 15,7 & 67,2 & 541,1 \\
Inverno & 19,6 & 59,4 & 1311,9 \\
Média & 21,3 & 68,7 & 780,5 \\
Desvio-padrão & 0,8 & 4,7 & 265,7 \\
\hline
\end{tabular}

o hábito epifítico entre as espécies inventariadas (AGUIAR et al., 1981; PINTO et al., 1995; DISLICH; MANTOVANI, 1998; KERSTEN; SILVA, 2001, 2002; PANSARIN; PANSARIN, 2008), diferindo do Cerrado, onde predominam espécies terrícolas (BATISTA; BIANCHETTI, 2003; BATISTA et al., 2005).

As características de luminosidade, temperatura e umidade relativa apresentaram valores de acordo com o padrão registrado para a região de Dourados, MS, considerando-se que as aferições foram realizadas em condições de sub-bosque (SEPLAN, 1990). No que concerne à quantidade de luz no sub-bosque, foi verificado um gradiente, no qual o inverno, em função da deciduidade parcial da vegetação, ficou caracterizado pela maior iluminação do solo, contrapondo-se ao verão. No outono e na primavera ocorreram níveis intermediários de luminosidade no sub-bosque, seja pela queda progressiva das folhas, seja pela rebrota, respectivamente.

Os gradientes inversos de luminosidade e umidade estabelecidos entre o dossel e a parte do fuste próxima ao solo (PARKER, 1995) estão entre os fatores determinantes da distribuição vertical de epífitas sobre forófitos na região tropical (KERSTEN; SILVA, 2001). Embora não tenha sido avaliada a existência de tal gradiente neste estudo, algumas espécies parecem apresentar tendências opostas de ocupação dos diferentes níveis de altura que poderiam estar relacionadas com aquele gradiente. Tanto Bulbophyllum spp. quanto Acianthera recurva preferencialmente ocupam os níveis superiores, diminuindo a representatividade em direção ao solo, enquanto Acianthera aff. macuconensis, Laelia lundii e Macradenia multiflora tendem a ocupar os estratos mais próximos ao solo. Acianthera pubescens foi registrada 
ocupando preferencialmente o nível de altura intermediário. Outras espécies como Capanemia micromera e Trichocentrum pumilum parecem não ser influenciadas pelo gradiente luminoso, uma vez que ocorrem com aproximadamente a mesma frequência nos diferentes níveis de altura avaliados (Tabela 1). As demais espécies, dada a baixa abundância, não permitem inferências.

Com relação à disposição cardeal das plantas em torno dos forófitos, percebe-se que espécies com abundância maior apresentaram tendência de se distribuírem mais homogeneamente em torno dos forófitos, e. g. Brassavola ceboletta e Acianthera aff. macuconensis. Nesse sentido, a ocorrência preferencial em uma das faces do forófito pode ser artefato oriundo de insuficiência amostral. No entanto, acredita-se que a localização do espelho d'água a sul dos forófitos poderia contribuir com a diminuição da umidade na face oposta (norte) e ajudaria a explicar a menor ocorrência das plantas especificamente na face norte. Essa perspectiva estaria de acordo com a proposta de Callaway et al. (2002), quando indicaram a disponibilidade hídrica como fatorchave do estabelecimento de epífitos sobre forófitos.

Dada a importância das orquídeas na perspectiva conservacionista (“flag-family”), somente quando há conhecimento sobre o hábitat, ecologia e tamanho das populações se pode planejar estratégias de conservação apropriadas (JACOBI et al., 2008; DIXON et al., 2003). Este estudo apontou para a necessidade de se aumentar o conhecimento acerca da flora de Mato Grosso do Sul, a fim de subsidiar estratégias adequadas de preservação da diversidade florística dos ecossistemas naturais. Essa necessidade se acentua à medida que o Estado, bem como toda a área de ocorrência da Floresta Estacional Semidecidual, encontra-se fortemente antropizado, especialmente para fins de agricultura (LEITE; RODRIGUES, 2008). De forma que, se a perspectiva atual de avanço das áreas agrícolas se mantiver em breve, o Estado poderá, de fato, tornar-se uma área “pobre” em orquídeas, como afirmaram Hoehne (1923) e Hoehne e Kuhlmann (1951).

\section{AGRADECIMENTOS}

Ao Dr. Fabio de Barros, pela oportunidade de estágio ao primeiro autor; ao Dr. Rodrigo Singer, pelo incentivo no início do trabalho; à Caroline Scherer e Mariana Franco Cassino, pela leitura da versão original e pelas sugestões; a Jackeline Soares, Mariana Tatara e Sonia Aragaki, pelo auxílio com a bibliografia; e a Carlos D’Apolito, pelo auxílio com o inglês.

\section{REFERÊNCIAS}

AGUIAR, L. W. et al. Composição florística de epífitos vasculares numa área localizada nos municípios de Montenegro e Triunfo, Rio Grande do Sul, Brasil. Iheringia Série Botânica, v.28, n.1, p.55-93, 1981.

BATISTA, J. A. N.; BIANCHETTI, L. B. Lista atualizada das Orchidaceae do Distrito Federal. Acta Botanica Brasilica, v.17, n.2, p.183-201, 2003.

BATISTA, J. A. N.; BIANCHETTI, L. B.; PELLIZARO, K. F. Orchidaceae da Reserva Biológica do Guará, DF, Brasil. Acta Botanica Brasílica, v.19, n.1, p.221-232, 2005.

BORGO, M.; SILVA, S. M. Epífitos vasculares em fragmentos de Floresta Ombrófila Mista, Curitiba, Paraná, Brasil. Revista Brasileira de Botânica, v.26, n.3, p.391-401, 2003.

BRASIL. LEI N ${ }^{\circ}$ 4.771, de 15 de setembro de 1965 (Código Florestal Brasileiro). D. O. U. 16 set. 1965. Disponível em http://www.planalto.gov.br/ ccivil_03/LEIS/L4771.htm. Acesso em 31 jul. 2009.

CARDOSO, J. C.; ISRAEL, M. Levantamento de espécies da família Orchidaceae em Águas de Sta. Bárbara (SP) e seu cultivo. Horticultura Brasileira, v.23, n.2, p.169-173, 2005.

DISLICH, R.; MANTOVANI, W. Flora de epífitas vasculares da Reserva da Cidade Universitária “Armando de Salles Oliveira” (São Paulo, Brasil). Boletim de Botânica da Universidade de São Paulo, v.17, p.61-83, 1998.

DITTRICH, V. A. O.; KOZERA, C.; SILVA, S. M. Levantamento florístico de epífitos vasculares no Parque Barigüi, Paraná, Brasil. Iheringia (Série Botânica), v.52, p.11-22, 1999.

DIXON, K. W. et al. Orchid conservation. Natural history publications (Borneo), Kota Kinabalu: Sabah, 2003. p.1-24.

GENTRY, A. H. Changes in plant community diversity and floristic composition on environment and geographical gradients. Annals of the Missouri Garden, v.75, p.1-34, 1988.

GIULIETTI, A. M. et al. Biodiversidade e conservação das plantas no Brasil.

Megadiversidade, v.1, n.1, p.52-61, 2005. 
HOEHne, F. C. Phytophysionomia do Estado de Mato Grosso e ligeiras notas a respeito da composição e distribuição da sua flora. Edição Única. São Paulo: Companhia Melhoramentos, 1923. 94p.

HOEHNE, F. C.; KUHLMANN, J. G. Índices bibliográficos e numéricos das plantas colhidas pela Comissão Rondon. Edição Única. São Paulo: Secretaria da Agricultura do Estado de São Paulo/ Instituto de Botânica de São Paulo, 1951. p.164-181.

JACOBI, C. M.; CARMO, F. F.; VINCENT, R. C. Estudo fitossociológico de uma comunidade vegetal sobre canga como subsídio para a reabilitação de áreas mineradas no quadrilátero ferrífero, MG. Revista Árvore, v.32, n.2, p.345-353, 2008.

JACOVINE, L. A. G. et al. Quantificação das áreas de preservação permanente e de reserva legal em propriedades da bacia do Rio Pomba-MG.

Revista Árvore, v.32, n.2, p.269-278, 2008.

JUDD, W. S. et al. Plant systematics: a phylogenetic approach. 3.ed. Porto Alegre: Artmed, 2002. 612p.

KERSTEN, R. A.; SILVA, S. M. Floristic composition and structure of the vascular epiphyte component of a subtropical ombrophilous alluvial forest of Barigüi river, Paraná, Brazil. Revista Brasileira de Botânica, v.25, n.3, p.259-267, 2002.

KERSTEN, R. A.; SILVA, S. M. Florística e estrutura do componente epifítico vascular em floresta ombrófila mista aluvial do rio Barigüi, Paraná, Brasil. Revista Brasileira de Botânica, v.25, n.3, p.259-267, 2001.

LEITE, E. C.; RODRIGUES, R. Fitossociologia e caracterização sucessional de um fragmento de floresta estacional no sudeste do Brasil. Revista Árvore, v.32, n.3, p.583-595, 2008.

LIMA, J. G. A. Orquídeas do Estado de Mato Grosso. In: ENCONTRO NACIONAL DE ORQUIDÓFILOS E ORQUIDÓLOGOS, 2., 1985, Recife. Anais... Recife: Expressão e Cultura, 1985. p.82-98.

MENDONÇA, R. C. et al. (Ed.). Cerrado: ambiente e flora. Planaltina: Embrapa-CPAC, 1998. p.289-556.
PABST, G. F. J.; DUNGS, F. Orchidaceae Brasiliensis. Hildeshein: Brücke-Verlag Kurt Schmersow, 1975. v.1.

PABST, G. F. J.; DUNGS, F. Orchidaceae Brasiliensis. Hildeshein: Brücke-Verlag Kurt Schmersow, 1977. v.2.

PANSARIN, E. R.; PANSARIN, L. M. A família Orchidaceae na Serra do Japi, São Paulo, Brasil. Rodriguésia, v.59, n. 1, p.99-111, 2008.

PEREIRA, Z. V. et al. Estrutura fitossociológica do estrato arbustivo-arbóreo de um fragmento de Floresta Estacional Semidecidua no município de Dourados-MS. Revista Brasileira de Biociências, v.5, n.2, p.72-74, 2007.

PINTO, A. C.; DEMATTÊ, M. E. S. P.; PAVANI, M. C. M. D. Composição florística de epífitas (Magnoliophyta) em fragmento de floresta no município de Jaboticabal, SP, Brasil. Científica, v.22, n.1, p.283-289, 1995.

RIZZINI, C. T. Fitogeografia do Brasil. São Paulo: Hucitec, 1979.

SALIS, S. M. et al. Fitossociologia de remanescentes de floresta estacional decidual em Corumbá, Estado do Mato Grosso do Sul, Brasil. Revista Brasileira Botânica, v.27, n.4, p.671-684, 2004.

SEPLAN. Secretaria de Estado de Planejamento e de Ciência e Tecnologia. Atlas multirreferencial - Estado de Mato Grosso do Sul. Campo Grande: SEPLAN, 1990. 25p.

SILVA, L. A.; SCARIOT, A. Composição e estrutura da comunidade arbórea de uma floresta estacional decidual sobre afloramento calcário no Brasil central. Revista Árvore, v.28, n.1, p.69-75, 2004.

SPICHIGER, R.; CALENGE, C.; BISE, B. Geographical zonation in the Neotropics of tree species characteristic of the Paraguay-Paraná Basin. Journal of Biogeography, v.31, n.9, p.1489-1504, 2004.

TOZZO, S. A.; CARVALHO, S. A Família Orchidaceae em fragmentos da Mata Atlântica no Município de Congonhinhas. Orquidário, v.21, n.1, p.89-94, 2007. 